\title{
Correction to: Effect of taping on scapular kinematics of patients with facioscapulohumeral muscular dystrophy
}

Cevher Savcun Demirci ${ }^{1}$ Özge Onursal Kılınç ${ }^{2} \cdot$ Taha İbrahim Yıldız $^{2} \cdot$ Ender Ayvat $^{2} \cdot$ Fatma Ayvat $^{2}$ • Elif Turgut $^{2}$. İrem Düzgün ${ }^{2}$ - Sibel Aksu Yıldırım² ${ }^{2}$ Muhammed Kılınç²

Published online: 10 May 2019

(C) Fondazione Società Italiana di Neurologia 2019

\section{Correction to: Neurological Sciences 2019}

https://doi.org/10.1007/s10072-019-03846-y

The published version of this article unfortunately contained a mistake in Fig. 2. Only one graphic of different movement of scapula was published instead of three. The Figure is corrected here.

Publisher's note Springer Nature remains neutral with regard to jurisdictional claims in published maps and institutional affiliations.

The online version of the original article can be found at https://doi.org/ 10.1007/s10072-019-03846-y

Cevher Savcun Demirci

cevhersavcun@hotmail.com

1 Faculty of Health Sciences, Department of Physiotherapy and Rehabilitation, Kırıkale University, Kırıkale, Turkey

2 Faculty of Physical Therapy and Rehabilitation, Hacettepe University, Ankara, Turkey 

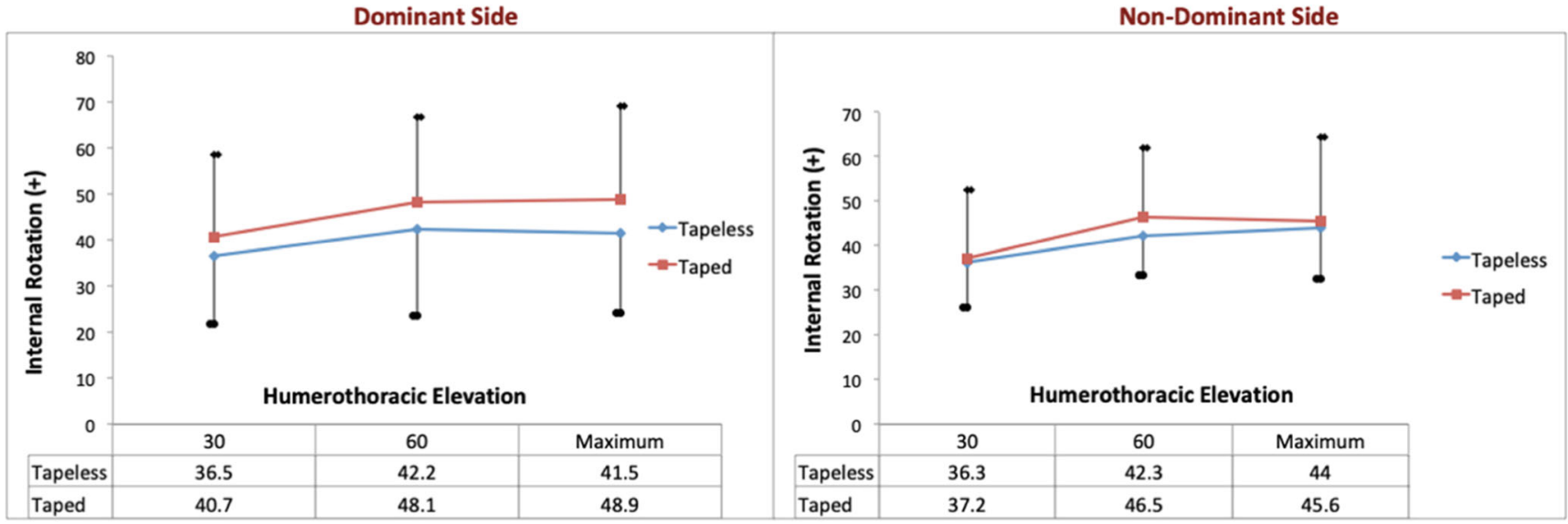

\section{Scapular internal rotation with and without taping}

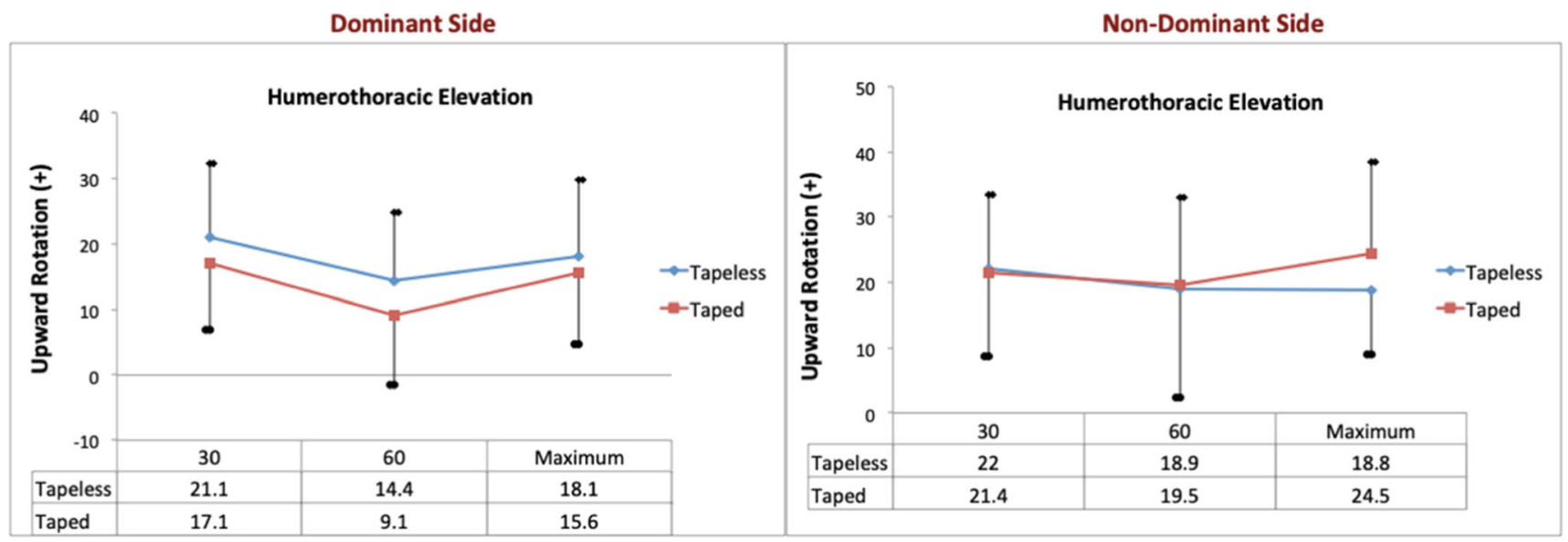

\section{Scapular upward rotation with and without taping}
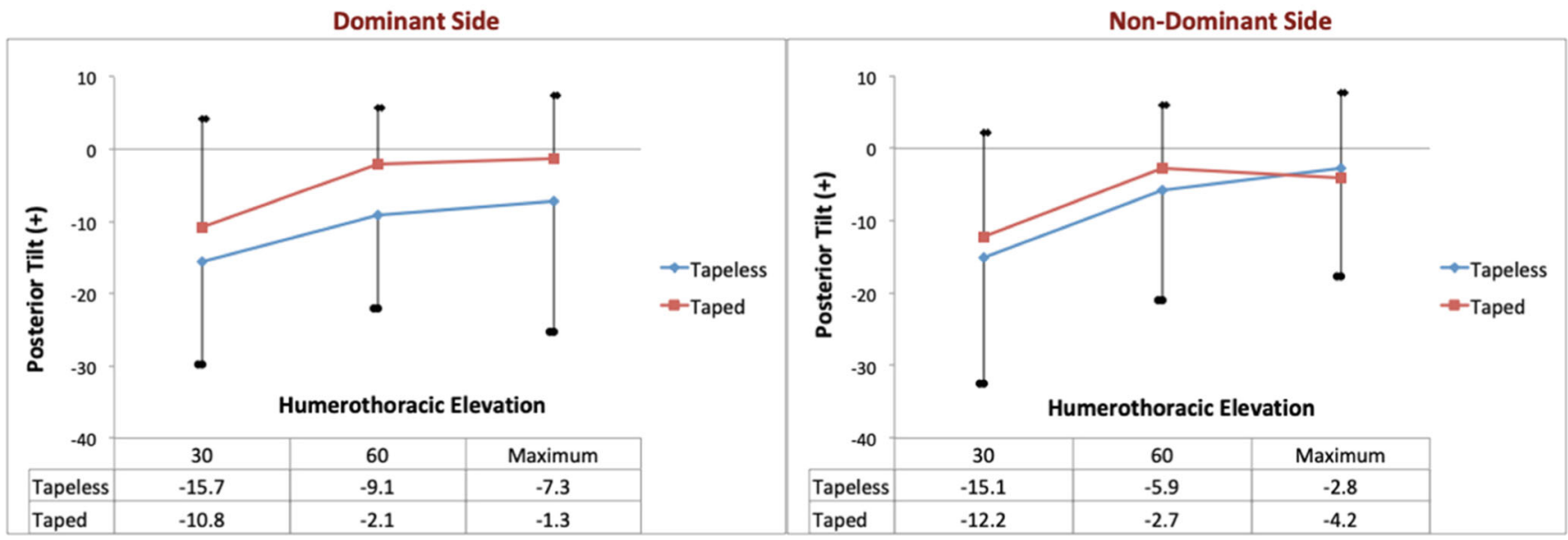

\section{Scapular posterior tilt with and without taping}

Fig. 2 Scapular internal/external rotation, upward/downward rotation, and anterior/posterior tilt during dominant and non-dominant side shoulder elevation of patients with FSHMD (with and without taping) 